\title{
Cost of Biotech Drug Development and Affordability Issues in LMICs
}

\author{
Abdul Kader Mohiuddin* \\ Department of Pharmacy, World University of Bangladesh, Bangladesh
}

*Corresponding author: Abdul Kader Mohiuddin, Department of Pharmacy, World

University of Bangladesh, Bangladesh.

Abbreviations: Partnership for Influenza Vaccine Introduction (PIVI); National Immunization Technical Advisory Groups (NITAGs); Out-of-pocket (OOP); Low-and Middle-Income Countries (LMICs); Randomized Control Trial (RCT); Human Papillomavirus (HPV); Gross Domestic Product (GDP); Essential Medicine List (EML); Research and Development (R\&D); Brazil, Russia, India, China and South Africa (BRICS countries).

\section{Mini Review}

Pharmaceutical companies invest in the development and testing of their drugs including by funding clinical trials. Furthermore, pharmaceutical companies also spend a large amount of money on advertising. For instance, in 2016 US $\$ 6.7$ billion was spent on direct-to-consumer pharmaceutical advertising alone in the USA [1]. Worldwide spending on medicines reached $\$ 1.2$ trillion in 2018 and will exceed $\$ 1.5$ trillion by 2023 , according to "The Global Use of Medicine in 2019 and Outlook to 2023" [2,3]. Although, access to essential medicines is problematic for one third of all persons worldwide [4]. Limited access to essential medicines (EMs) for treating chronic diseases is a major challenge in low- and middle-income countries (LMICs) [4,5]. Average public sector availability of even low-cost generic medicines ranges from $30 \%$ to $55 \%$ across 36 LMICs [6]. Price of drugs, vaccines, and diagnostics is a major burden in 105 middle income countries round the globe, comprising of $70 \%$ of the world population, $75 \%$ of the poor [7]. While public hospitals offer free or subsidized treatment including essential medicines, the high patient caseloads, underfunding and inefficient medicine distribution systems are barriers to consistent service provision [8]. Moreover, $90 \%$ of the population in developing countries purchase medicines through out-of-pocket (OOP) payments [7]. Poor availability of medicines in the public sector has pushed up household OOP expenditure, making them the largest household expenditure item after food [9]. However, The WHO has set a minimum of $80 \%$ as target availability of medicines for both communicable and non-communicable diseases in all countries [10]. But Pharmaceutical companies have a substantial desire in developing drugs for chronic diseases and cancer treatments, not only because of high prevalence, but also because these drugs are often used in long term [11]. Pharmaceutical patents maintain drug prices well above the cost of production and can restrict access to needed medicines [12]. Biotech drugs have completely changed the management of several diseases, including cancer and autoimmune diseases such as, psoriasis, rheumatoid arthritis, multiple sclerosis, and inflammatory bowel disease [13]. The high cost of biotech medications (target a gene or protein and typically are injected or infused, associated with treating a chronic condition) often requires significant OOP expenditures [14,15]. Some studies say that pharmaceutical companies price drugs monopolistically, protected by patent rights, while others believe that the high prices for orphan drugs simply allow drug R\&D and production costs. However, the global orphan drug market is estimated to reach US $\$ 209$ billion by 2022 accounting for $21.4 \%$ of total branded prescription drug sales [16]. According to the Tufts Center for Drug Development, it costs, on average, $\$ 100$ million in 1975 , around $\$ 900$ million before 2004 and 1.3 billion after 2005 to develop a new drug and bring it to market $[17,18]$. While, Scavone et.al, 2019 reported that entire time that passes from the R\&D phase until the drug's marketing approval can last up to 15 years, and it is characterized by extremely high costs, usually exceeding $\$ 1.2$ billion [19]. Gouglas et.al, 2018 
estimated a minimum of $\$ 2 \cdot 8-3 \cdot 7$ billion ( $\$ 1 \cdot 2$ billion- $\$ 8 \cdot 4$ billion range) for one vaccine through to the end of phase 2 a among 11 epidemic infectious diseases [20]. Apart from the traditional design of RCT, in recent years further study designs, including umbrella, basket and platform trials, were developed and applied to new therapies, especially in the area of oncology research [21]. Tay-Teo et.al, 2019 stated the most commonly accepted estimates of R\&D costs, including cancer drugs, are between $\$ 200$ million and \$2.9 billion, after adjustments for the probability of failure and opportunity costs [22]. Genomic studies conducted in the past two decades identified the molecular drivers of certain cancers and led to the advent of targeted therapies as an important additional pillar of the cancer therapy armamentarium [23]. According to the Global Oncology Trend Report, global spending on cancer medications rose from $\$ 75$ billion in 2010 to $\$ 100$ billion in 2014, 10.3\% rise in spending. Asia accounts for $60 \%$ of the world population and $50 \%$ of the global burden of cancer [24]. There are over 100 types of cancers, located in different organs and sub-tissues and originating from different cell types. Some cancer types (e.g., colon, breast, and non-Hodgkin's lymphoma) contain even more specific classifications based on their molecular subtypes. Despite this complexity and variability, most types of cancer are treated with the same generic therapies [25]. Critics claim that prices of innovative drugs are excessive and argue that lowering prices will not harm the flourishing innovation. On the opposite end, the pharmaceutical industry insists that restrictive pricing policies will have a detrimental impact on their ability to generate innovation [26]. During 2017, PIVI worked with its country partners and the WHO regional and local offices to assess NITAGs strengthening needs and to provide technical assistance in 7 LMICs (Laos Peoples Democratic Republic, Mongolia, Vietnam, Armenia, Côte d'Ivoire; Moldova and the Republic of Georgia) [27]. In Europe, total cancer drug sales more than doubled between 2005 and 2014, increasing from €8.0 billion to $€ 19.8$ billion [28]. Biologics were estimated to account for US $\$ 289$ billion pharmaceutical sales in 2014 and are projected to reach US\$445 billion in 2019. It is also anticipated that biologics' share of global prescription and over-the-counter pharmaceutical sales will rise to $26 \%$ by 2019 [29]. It is projected that new cases of cancer will increase from about 14 million in 2012 to 22 million in 2030, with most cases in LMICs located in Africa, Asia and Latin America [30]. The projected increase in cancer incidence is predicted to be most significant in LMICs in Asia. In these countries, over $60 \%$ of the total healthcare expenditure comes from private resources, of which more than $80 \%$ is direct OOP payments, with catastrophic results for most families in these countries [24]. In India alone, as many as 63 million people are forced into poverty every year, owing to catastrophic health expenses, the majority of which are 00P payments for medicines [31]. Genetic predisposition, increasing life expectancy, urbanization, mechanization, inadequate health services and rapid economic development fueling sedentariness and changing dietary patterns are contributing to rising chronic disease burden in the South Asian region [32]. Rijal et.al, 2018 reported that Afghanistan, Bangladesh, Bhutan, Maldives, Nepal, India, Pakistan and Sri Lanka, which are mostly LMICs with regional GDP per capita 1640 USD and home to a quarter of world population [33]. According to Giri et.al, 2018 breast cancer was the most prevalent cancer and fourth leading cause of cancer-related mortality among women in Asia [34]. Siegel et.al, 2019 states mortality rates in the poorest counties were 2-fold higher than most affluent counties for cervical cancer and $40 \%$ higher for male lung and liver cancers during 2012-2016 [35]. One-third of the world cervical cancer burden is endured in India, Bangladesh, Nepal and Sri Lanka. High-risk HPV types were found in $97 \%$ of cervical cancers, and HPV-16 and 18 were found in $80 \%$ of cancers in India [36]. Stomach cancer (9.0\%), breast cancer (8.2\%), lung cancer $(7 \cdot 5 \%)$, lip and oral cavity cancer $(7 \cdot 2 \%)$, pharynx cancer other than nasopharynx $(6 \cdot 8 \%)$, colon and rectum cancer $(5 \cdot 8 \%)$, leukemia $(5 \cdot 2 \%)$, and cervical cancer $(5 \cdot 2 \%)$ are the leading types of cancer in India in 2016 [37]. India has been well known in the global oncology community as the country where cancer drug prices are cheaper compared to other countries. For instance, the 4-weekly cost of trastuzumab was \$2761 in India versus \$6849 in the US [38]. It was indeed heartening to see that India paid $\$ 19000$ for a 4-week course of bevacizumab (based on purchasing power parity) while Australia paid only \$543 [39]. In the US, individuals diagnosed with cancer are 2.7 times more likely to declare bankruptcy, than individuals without cancer [40]. Saqib et.al, 2018 stated that patients in LMICs find it difficult to afford non-biologics and their treatment with new therapeutic agents like biologic is almost impossible. Therefore, the management of cancer is seriously affected by the availability and affordability of anticancer agents [41]. Due to lack of information on comparative drug prices and quality, it is difficult for physicians to prescribe the most economical treatment. Lack of information on quality, nonavailability and conflicts of interest are also responsible for physicians not prescribing the least expensive medication. The difference in cost between the various brands of the same drug varies from 2- fold to more than 100-fold in India [42]. Bhutan (13\%), Maldives (5\%) and Timor-Leste (5\%) - are small countries with challenging geographies that lack the capacity for local pharmaceutical production. They may also use alternative strategies, such as sending patients with cancer for treatment abroad [25]. Many examples of high drug prices exist and are frequently discussed in the media. One often mentioned example is imatinib (brand name Gleevec $®$ ), a drug for chronic myeloid leukemia, which tripled in cost after the US FDA allowed for a new indication. Novartis raised its price from \$31,930 in 2005 to $\$ 118,000$ per year in 2015 despite a huge increase in the volumes sold [43]. The 19th revision of the WHO EML in 2015 added 16 essential cancer drugs, including three high-cost medicines, imatinib, rituximab and trastuzumab, and therefore improving equitable access to innovative treatments for cancer that are widely unavailable in low-resource settings [44]. India is one of the top global funders of R\&D into neglected diseases, according to Thomas et.al, 2019 . Nearly $12 \%$ of drug, diagnostic, and vaccine candidates for neglected diseases in the R\&D pipeline are from India [45]. Most South Asian countries have well laid out regulatory pathways for biosimilar approval. While no biosimilar insulin is approved in USA 
as of date August 2015, the European Medicines Agency and Japanese drug regulatory authorities have given approval to only one insulin-a biosimilar insulin glargine produced by Eli Lilly [46]. One of the most significant safety concerns with biosimilars is the potential risk of immune-based adverse reactions. Because of their molecular size, biologics can directly induce anti-drug antibodies which may have significant consequences for both safety and efficacy [47]. As manufacturers of biosimilar products do not have access to the cell line and technique of reference product, the manufacturing process may change slightly, but this may have tremendous impact on the biological function of the product, including immunogenicity, potentially affecting the safety and efficacy profile [48]. Also, the costs of drug distribution in India are 2 to 3 times greater than in the United States or the European Union, despite vastly lower labor costs. Their staff are not required to show skills in pharmaceutical warehousing and management, often with disastrous consequences [49]. The monthly drug prices were the highest in the U.S and lowest in India. However, despite having the lowest drug prices, drugs were the least affordable (affordability estimated as drug prices divided by GDP per capita or average salary) in India [38,39]. Those drugs that ensure cure should be given the first priority. The governments and policy makers in LMICs should prioritize access to highly effective biotech drugs used in curative setting and limit spending on costly but ineffective or minimally effective drugs used in palliative setting. Inter collaborations between the BRICS countries like Brazil, China and India need to set the pace and create more incentives to increase local production of drugs with LMICs [50]. There are various interventions or changes in policies advised that can help in lowering the cost of biotech drugs like breaking the monopoly in drug manufacturers, changing the regulatory guidelines by government agencies in favor of those companies which manufacture cheaper drugs and making the new drug approvals faster, increasing the cost effectiveness ratio of drugs, achieving a balance between physician autonomy in prescribing biotech drugs and costs incurred by patients, encouraging non-profit generic companies which manufacture biotech drugs by giving them tax incentives and other measures, value based reimbursement by medical insurance companies.

\section{Acknowledgement}

I'm thankful to Gautam Kumar Saha, Apollo Hospitals Educational and Research Foundation, New Delhi, India for his precious time to review my letter to the editor and for his thoughtful suggestions. I'm also grateful to seminar library of Faculty of Pharmacy, University of Dhaka and BANSDOC Library, Bangladesh for providing me books, journal and newsletters.

\section{Conflict of Interest}

The author declares that he has no competing interests.

\section{References}

1. Beck EJ, Mandalia S, Dongmo Nguimfack B, Pinheiro E, Boulet P, et al. (2019) Does the political will exist to bring quality-assured and affordable drugs to low- and middle-income countries? Glob Health Action. 12(1): 1586317.
2. Philippidis A (2019) TOP 15 Best-Selling Drugs of 2018 Sales for most treatments grow year-over-year despite concerns over rising prices. GEN Magazine.

3. (2019) IQVA. The Global Use of Medicine in 2019 and Outlook to 2023: Forecasts and Areas to Watch. Institute Report.

4. Stevens H, Huys I (2017) Innovative Approaches to Increase Access to Medicines in Developing Countries. Front Med (Lausanne) 4: 218.

5. Faruqui N, Martiniuk A, Sharma A, Sharma C, Rathore B, et al. (2019) Evaluating access to essential medicines for treating childhood cancers: a medicines availability, price and affordability study in New Delhi, India. BMJ Glob Health. 4(2): e001379.

6. Lexchin J (2013) Canada and access to medicines in developing countries: intellectual property rights first. Global Health 9: 42 .

7. Moon S (2017) Powerful Ideas for Global Access to Medicines. N Engl J Med 376(6): 505-507.

8. Prinja S, Bahuguna P, Tripathy JP, Kumar R (2015) Availability of medicines in public sector health facilities of two North Indian States. BMC Pharmacol Toxicol 16: 43.

9. Oberoi SS, Oberoi A (2014) Pharmacoeconomics guidelines: The need of hour for India. Int J Pharm Investig 4(3): 109-11.

10. Khuluza F, Haefele-Abah C (2019) The availability, prices and affordability of essential medicines in Malawi: A cross-sectional study. PLoS One 14(2): e0212125.

11. Ahmadiani S, Nikfar S (2016) Challenges of access to medicine and the responsibility of pharmaceutical companies: a legal perspective. Daru 24(1): 13.

12. T Hoen EFM, Kujinga T, Boulet $P$ (2018) Patent challenges in the procurement and supply of generic new essential medicines and lessons from HIV in the southern African development community (SADC) region. J Pharm Policy Pract 11: 31

13. Scavone C, Sportiello L, Sullo MG, Ferrajolo C, Ruggiero R, et al. (2017) BIO-Cam Group. Safety Profile of Anticancer and Immune-Modulating Biotech Drugs Used in a RealWorld Setting in Campania Region (Italy): BIO-Cam Observational Study. Front Pharmacol 8: 607.

14. Goldman DP, Joyce GF, Lawless G, Crown WH, Willey V (2006) Benefit design and specialty drug use. Health Aff (Millwood). 25(5): 1319-1331.

15. Vogenberg FR, Young C (2004) Biotech injectable drugs: clinical applications and financial effects. Biotechnol Healthc 1(3): 31-40.

16. Jayasundara K, Hollis A, Krahn M, Mamdani M, Hoch JS, et al. (2019) Estimating the clinical cost of drug development for orphan versus nonorphan drugs. Orphanet J Rare Dis 14(1): 12.

17. Edelman B (2004) Explaining the cost of biotech therapies. Biotechnol Healthc 1(2): 37-41.

18. Kunnumakkara AB, Bordoloi D, Sailo BL, Roy NK, Thakur KK, et al (2019) Cancer drug development: The missing links. Exp Biol Med (Maywood). 244(8): 663-689.

19. Scavone C, Di Mauro G, Mascolo A, Berrino L, Rossi F, et al. (2019) The New Paradigms in Clinical Research: From Early Access Programs to the Novel Therapeutic Approaches for Unmet Medical Needs. Front Pharmacol 10: 111.

20. Gouglas D, Thanh Le T, Henderson $K$, Kaloudis A, Danielsen T, et al. (2018) Estimating the cost of vaccine development against epidemic infectious diseases: a cost minimisation study. Lancet Glob Health 6(12): e1386-e1396.

21. Simon R (2017) Critical Review of Umbrella, Basket, and Platform Designs for Oncology Clinical Trials. Clin Pharmacol Ther 102(6): 934941.

22. Tay-Teo K, Ilbawi A, Hill SR (2019) Comparison of Sales Income and Research and Development Costs for FDA-Approved Cancer Drugs Sold by Originator Drug Companies. JAMA Netw Open 2(1): e186875.

23. Kaufman HL, Atkins MB, Subedi P, Wu J, Chambers J, et al. (2019) The promise of Immuno-oncology: implications for defining the value of cancer treatment. J Immunother Cancer 7(1): 129. 
24. Salmasi S, Lee KS, Ming LC, Neoh CF, Elrggal ME, et al. (2017) Pricing appraisal of anti-cancer drugs in the South East Asian, Western Pacific and East Mediterranean Region. BMC Cancer 17(1): 903.

25. Chivukula MV, Tisocki K (2018) Essential cancer medicines in the national lists of countries of the WHO South-East Asia Region: a descriptive assessment. WHO South East Asia J Public Health 7(2): 9098.

26. Krzyszczyk P, Acevedo A, Davidoff EJ, Timmins LM, Marrero-Berrios I, et al. (2018) The growing role of precision and personalized medicine for cancer treatment. Technology (Singap World Sci) 6(3-4): 79-100.

27. Moreno SG, Epstein D (2019) The price of innovation - the role of drug pricing in financing pharmaceutical innovation. A conceptual framework. J Mark Access Health Policy 7(1): 1583536.

28. Ba-Nguz A, Shah A, Bresee JS, Lafond KE, Cavallaro K, et al. (2019) Supporting national immunization technical advisory groups (NITAGs) in resource-constrained settings. New strategies and lessons learned from the Task Force for Global Health's Partnership for influenza vaccine introduction. Vaccine 37(28): 3646-3653.

29. Owoeye O, Owoeye O (2018) Biologics and Public Health: Prospects and Challenges. JLaw Med 26(1): 170-187.

30. Wilking N, Lopes G, Meier KSS (2017) Can we continue to afford cancer treatment? Eur Oncol Hematol. 13(2): 114-119.

31. Barrios CH, Reinert T, Werutsky G (2019) Access to high-cost drugs for advanced breast cancer in Latin America, particularly trastuzumab. E cancer medical science 13: 898.

32. Paudel S, Owen AJ, Owusu-Addo E, Smith BJ (2019) Physical activity participation and the risk of chronic diseases among South Asian adults: a systematic review and meta-analysis. Sci Rep 9(1): 9771.

33. Rijal A, Adhikari TB, Khan JAM, Berg-Beckhoff G (2018) The economic impact of non-communicable diseases among households in South Asia and their coping strategy: A systematic review. PLoS One 13(11): e0205745.

34. Giri M, Giri M, Thapa RJ, Upreti B, Pariyar B (2018) Breast Cancer in Nepal: Current status and future directions. Biomed Rep 8(4): 325-329.

35. Siegel RL, Miller KD, Jemal A (2019) Cancer statistics, 2019. CA Cancer J Clin 69(1): 7-34.

36. Sankaranarayanan R, Bhatla N, Gravitt PE, Basu P, Esmy PO, et al. (2008) Human papillomavirus infection and cervical cancer prevention in India, Bangladesh, Sri Lanka and Nepal. Vaccine 26 Suppl 12: M43-52.

37. (2018) India State-Level Disease Burden Initiative Cancer Collaborators. The burden of cancers and their variations across the states of India: The
Global Burden of Disease Study 1990-2016. Lancet Oncol 19(10):12891306

38. Gyawali B (2017) Cancer drugs in LMICs: cheap but unaffordable. Oncotarget 8(52): 89425-89426.

39. Goldstein DA, Clark J, Tu Y, Zhang J, Fang F, et al. (2017) Stemmer SM, Rosenbaum E. A global comparison of the cost of patented cancer drugs in relation to global differences in wealth. Oncotarget 8(42): 7154871555 .

40. Ramsey S, Blough D, Kirchhoff A, Kreizenbeck K, Fedorenko C, et al. (2013) Washington State cancer patients found to be at greater risk for bankruptcy than people without a cancer diagnosis. Health Aff (Millwood) 32(6): 1143-52

41. Saqib A, Iftikhar S, Sarwar MR (2018) Availability and affordability of biologic versus non-biologic anticancer medicines: a cross-sectional study in Punjab, Pakistan. BMJ Open 8(6): e019015.

42. Kolasani BP, Malathi DC, Ponnaluri RR (2016) Variation of Cost among Anti-cancer Drugs Available in Indian Market. J Clin Diagn Res 10(11): FC17-FC20.

43. Gronde TV, Uyl-de Groot CA, Pieters T (2017) Addressing the challenge of high-priced prescription drugs in the era of precision medicine: A systematic review of drug life cycles, therapeutic drug markets and regulatory frameworks. PLoS One 12(8): e0182613.

44. Eniu A, Torode J, Magrini N, Bricalli G (2016) Union for International Cancer Control EML Steering Committee Members. Back to the 'essence' of medical treatment in oncology: the 2015 WHO Model List of Essential Medicines ESMO Open 1(2): e000030.

45. Thomas Z, Saha GK, Gopakumar KM, Ganguly NK (2019) Can India lead the way in neglected diseases innovation? BMJ. 364: k5396.

46. Kalra S, Azad Khan AK, Raza SA, Somasundaram N, Shrestha D, et al. (2016) Biosimilar insulins: Informed choice for South Asia. Indian J Endocrinol Metab 20(1): 5-8.

47. Abdul Kader Mohiuddin (2019) Safety Issues of Biosimilar Products. J Cancer Res Therap Oncol 7: 1-4.

48. Kaduskar PU (2016) Biosimilar insulins: An unavoidable option in South-East Asia. Indian J Endocrinol Metab 20(4): 574-575.

49. https://www.ncbi.nlm.nih.gov/books/NBK202530/

50. Ezziane Z (2014) Essential drugs production in Brazil, Russia, India, China and South Africa (BRICS): opportunities and challenges. Int J Health Policy Manag 3(7): 365-370. 